\title{
Ethics in Geographical Research: Studying Male Homosexual Cruising Sites
}

\author{
Kiran Bhairannavar
}

Department of Geography, University of Delhi, India

Received: 19 Dec 2020; Received in revised form: 21 Feb 2021; Accepted: 09 Mar 2021; Available online: 26 Mar 2021

C2021 The Author(s). Published by Infogain Publication. This is an open access article under the CC BY license

(https://creativecommons.org/licenses/by/4.0/).

\begin{abstract}
The paper focuses on the ethical considerations while researching on geographies of sex. It highlights the key tensions between method and research ethics. Focusing on homosexual men's sexual cruising sites, it reflects on the application of ethical practices while undertaking research on sensitive places produced by sexually marginalized groups. The paper argues for an expansive reading of ethics in practice. The paper is divided into three sections. Section one deals with ethics in human geography research. Section two focuses on ethical practices in sexuality research. Section three brings out the questions that arise while undertaking research on the field and draws on works of scholars who have used justifiable ways to find answers.
\end{abstract}

Keywords—Ethics, Fieldwork, Human Geography, Methodology, Sex.

\section{INTRODUCTION}

The paper focuses on ethical issues involved in researching sexual spaces in the context of human geography research. It highlights the methodological aspects of conducting research on homosexual men's spaces. Homosexuals are often socially stigmatized and criminalized in many societies, forcing them to go invisible. As a result, they are known to produce spaces that are transient and sensitive, often subverting heterosexual space (Bhairannavar, 2016). The paper looks into the ethical practices involved in human geographical research and their application to the study of sexualities. It brings to discussion certain contexts that can make ethical modes of generating data a significant challenge while undertaking fieldwork. The paper calls for an expansive reading of ethical practices that can be inclusive and at the same time sensitive. The paper is in three parts. In section one, I briefly discuss ethical practices in geographical research to build a context as to what constitutes ethics and how geographers are in agreement on certain protocols. In section two, I look into the ethical practices in (geographical) studies on sexualities. Thirdly, I focus on certain questions that arise while doing fieldwork in spaces where sex is solicited and practiced.

\section{ETHICS AND GEOGRAPHICAL RESEARCH}

Ethics have increasingly become a crucial part of research especially where human participants are involved (Trudi and Platzer, 1999). Research ethics refers to perspectives on proper conduct of researchers during their interactions with research participants, and the social, emotional and political consequences of research methods used. These include two types, namely, universalist ethics and situational ethics. Universalist ethics are universally applied and upheld. Situational ethics are contextual to specific circumstances (Dowling, 2009, p. 595). The key ethical issues in human geography generally focus on the conduct of the research and the treatment of research participants. There is a widespread agreement within social sciences in general and human geography in particular on certain core ethical practices like receiving informed consent, avoiding harm to research participants/ communities and the researcher, acknowledging the power relations between the two, and issues of confidentiality and trust. Informed consent is where the participants are informed about the research and have consented to be a part of the project. This is to rule out any type of deception on the part of the researcher and covert nature of research. It is a widely acknowledged that research involves power 
relations between the researcher and researched which needs to be constantly reflected upon by the researcher during the process. Care should be taken as to not exploit the situation for one's own advantage. Since the participants give time, opinions and information, it is widely accepted in the research community to make up for this by giving back to the community either by involving them as more than just research respondents, or making financial payments (though this is debatable) or initiating measures for positive change in the community. However, more than giving back, it is the beneficence that matters significantly in any given research which means not to harm or do evil to the researched in anyway (Lenza, 2004). Furthermore, it is well accepted in the community of professional geographers that research needs to be sensitive especially if the researched communities are vulnerable, cross-cultural, young, marginalized and socially stigmatized. To do away with potential harm and keep their trust in place, participants need to be guaranteed anonymity and confidentiality. Their details need to be protected and not released to the public domain. Their crucial details are changed in order to prevent identification. A peculiar take by geographers on the anonymity ethic is identification of places which is central to the agenda of geographical inquiry. Many geographers (see Crang, 1994) have used pseudonyms to remove identification of places to avoid potential problems (Dowling, 2009, p. 598).

\section{DOING RESEARCH ON SEXUALITY: ETHICAL CONSIDERATIONS}

Research on sexualities is sensitive given the nature of the subject. Questions have been raised on the methods to be employed in research and (re)presentations, and the ethical underpinnings of the same. Researching on marginal nonnormative sexualities is often a difficult project due to the ethical issues involved, the recruitment of research participants, the positionality of the researcher and the audience to whom the research is to be presented. Given that these communities are socially stigmatized, invisible, marginalized and criminalized at varying degrees in many societies and States, such negative attitudes might well get reflected in academic endeavors which can have damaging consequences for both the researcher and the researched. These can manifest through means of refusal of supervision and funding to the project, homophobic and transphobic panic on part of people in power (university faculty, research boards), and stigma and ostracization of the researcher. For the communities researched, there is always a possibility of harm involved through outing them to the general public or studying and misrepresenting them using methods that are unsuitable. These are prominent issues that can harm the researched communities and compromise the confidence of the researcher. Yet a considerable research has been undertaken within and outside geography looking into various dimensions of nonnormative sexualities (homosexualities) like casual gay sex among men (Humphrey, 1970), lesbian and gay men's living in the city (Adler and Brenner, 1992), gay male urban history of New York city (Chauncey, 2008), psychoanalysis of male homosexuality (Bech, 1997), gay men's closet (Brown, 2000), gay men's use of the Internet (McLelland, 2002; Campbell, 2004; Shahani, 2008), gay men's cruising in the U.K. (Brown, 2008) etc.

A focus on the ethical standards these studies employed helps to shed some light. Adler and Brenner (1992) in their study of lesbian and gay men do not identify the place of their research. The reason being 'that some lesbians and gay men might not have wanted their communities [locationally] "outed" and there was the real fear of reprisals, including physical attack' (England, 1994, p. 84). Similarly, in his study on gay men's closet in Christchurch, Brown (2000), conceals the name of gay bars and the streets they are located on. Campbell (2004) uses code names to address his research participants in the study of online gay chat rooms. Valentine et al. (2001) in their study on young gay and lesbians note the methodological difficulties in holding interviews especially in spaces of home and school which were spaces where their research participants spent most of their time. Instead, they found community spaces and gay and lesbian friendly venues as apt to hold sensitive conversations. They also used email as an important way of communicating and working with some young gay and lesbian persons. Furthermore, they took great care in anonymizing all the material arising from the project including notes and transcripts stored in the data files. Lastly, they made themselves aware of the need to tailor their way in disseminating their findings such that it avoided breaching the participant's confidentiality. In the study on sexuality and the Internet in Delhi, Bhairannavar (2010) not only took great care in crafting the methodology to generate data through a gay networking site, but also was sensitive enough in disseminating the findings, especially the presentation part of it. Most images used to represent the findings were anonymized by removing all identifications and references. A pseudonym was used for the gay networking site, as most the members in the audience for whom the findings were to be presented were supposedly "straight" and resided in Delhi where the research was undertaken. Any identification of the site would have meant outing the site as homosexual and putting the user-community in danger in a society which was largely homophobic at the time. The researcher also 
invited the participants of the research to attend the presentation of findings, as a sign of giving back, showing gratitude and to witness their voices being represented.

The ethical practices in the above studies are quiet conforming to the wider spirit of ethics making it safe and un-harming to the researched communities. Researchers studying sexualities have taken great care to be sensitive to people and places they have studied. Yet in some contexts, aims of research, methods and ethical standards rarely fit onto each other as neatly. They can be at tensions with each other while generating data on the field. What I am interested in here is the tensions that arise while using a certain research method and the ethical standards they might potentially breach. In the next section, I highlight some challenges that came up while undertaking research on homosexual cruising and sites of public sex in Delhi.

\section{TENSIONS ON THE FIELD}

My research on Delhi's queer (male homosexual) spaces was based on observations in cruising areas/ sites of public sex, advocacy spaces, saunas, Internet spaces and gay party scenes apart from in-depth interviews with research participants (Bhairannavar, 2016). Many questions arose in this context. I shall discuss one of spaces namely cruising areas/ sites of public gay sex in Delhi and the ethical tensions I faced on the field.

Cruising areas are public spaces where men solicit for sex. With social condemnation and homophobia in the Indian society, these spaces become important part of homosexual men's lives. Here, men find each other and sexually express their desires. Cruising areas are mostly located at busy junctions like bus terminals, railway stations, parks and public toilets where the population of men is in constant circulation. The main function of these spaces is sexual. Cruising depends on factors of anonymity and constant movement of men in these places where sexual contacts can be made without giving out one's identity. A sign language like eye contact, hand gestures, touching one's own genitalia or having a pick-up line, or some sort of an indication are means used to show sexual interest. If the match happens, men involve in sex on-site (for example inside public toilets) or in an isolated area nearby which is appropriated for sex (for example, a park or space between buildings with not much light and visitors). My research method involved participant observation, generating data on how men cruised and participated in sex, the spaces they occupied and the tactics they used. The cruising area was located adjacent to a bus depot and was characterized by constant movement of people. The key questions of ethical practice that stood in tension were, firstly, in terms of informed consent, whose consent the researcher needs to take when observations are being made of public places like parks and toilets? Secondly, in terms of deception, how can the researcher's intensions be made overt in a context where unknown people constantly moved in and out? How best can one capture the dynamics of the place if the researcher's status is overt, especially in places like cruising/ sexual sites? These questions are serious given the nature of the field site. Public sex is not only socially looked down upon, but also constantly under the heterosexual State's surveillance, attracting penalties or abuse by those in power- Police and other regulatory authorities. Such a nature makes these places loaded with a sense of risk that hovers on the participants, for whom the implications of being caught are real and dangerous to their social reputation and safety. As such any activity that documents or even observes such sexual ecologies might not only attract suspicion on part of the participants but also disrupt the happenings in the place or at worst, destroy its credibility. As noted in previous sections, it is our responsibility to be sensitive to the production of such spaces, not bringing harm to its participants or disrupting the milieu of the place.

I decided to keep my observations covert, be present in the place as a potential participant in the cruising scene and fore go the ethic of receiving consent. There are several studies that support this decision. In his study on cruising areas in the United Kingdom, Brown (2008) uses covert method of observation and justifies it as 'the most ethical approach, as it minimized disruption to the sites and presented no risk to the individual men who were cruising them' (p. 917). Such an action must be seen as situational and expansive rather than unethical, as it serves the best interest of the place without disrupting the happenings, even as it keeps the research going. My position as a fellow cruiser helped me blend in while posing no harm to the participants. McLelland (2002) studying Japanese gay men, takes the position of a researcher, lover, friend, sex friend from the onset in order to meet his research participants. He also describes his sexual encounters as a part of the research process and data generation (p. 388). He draws on the work of Carrier (1995) who identified himself as joto (queer) to his homosexually identified informants.

Once identified as joto, Carrier was marked as a potential passive insertee for heterosexually identified men. He was thus able to experience and observe first-hand the sexual strategies employed by heterosexually identified males who have sex with men. However, in his more orthodox role as 'researcher' he had found it impossible to get these men to discuss their covert sexual practices with him, such 
information had only been available secondhand via his homosexual informants (McLelland, 2002, pp. 388-89).

Brown, Carrier and McLelland justify their need to be a part of cruising and sex respectively to understand the sexual practices of men. They push the ethical boundaries so as to be inclusive and sensitive to the contexts. In their justification, they defend it as the best possible way to generate data without bringing harm or disrupting peoples' lives or places. Here, the ethic of declaring the researcher's intension of data generation may affect the sexual ecology of the space. More so, such a position of being covert or taking multiple positions along with that of researcher, becomes a part of ethic enabling the study.

A similar research by Humphrey on 'Tea rooms' is often listed among the five famous cases of ethical controversy. The 1970's work became very unpopular for the "unethical" methods of data generation where the researcher studied a public toilet, stood a as a 'watch queen' and observed hundred men practicing casual sex. He took down their license plate numbers and traced the men whom he later interviewed disguised as a health survey agent. This study advanced the knowledge about homosexuals and overturned the previous false beliefs about Tearoom Trade. However, it was labelled as unethical for the participants never consented, deception was used and their names had every potential to be used to blackmail subjects, end marriages or initiate criminal prosecution (Neuman, 1997, p. 447). This dominant understanding of unethical research has been defended by Lenza (2004) who argues that the study did not violate the ethics of beneficence. His disguise as a health survey agent did violate the autonomy of participants but there were no professional or research guidelines requiring informed consent at that time when the study was conducted. Lenza notes, there was nothing exceptional about deception as it was used as a tool for producing exceptional works during those times (Lenza, 2004, p. 23). While Humphrey locked away all the details of the participants for wishing them no harm, the panic and potential harm, Lenza argues, was produced by his critics rather than the researcher himself.

\section{CONCLUSION}

This paper has discussed ethical issues in human geography research especially in relation to sexualities. I have highlighted as to what constitutes ethics in human geography/social science research and what are the ethical considerations followed in studies on sexualities. Geographers are in agreement on the ethical protocols while undertaking research and these involve place and participant centered protections. Based on my own research, I have brought out certain methodological contexts that come in tensions with the established ethical norms. It is defended by providing evidences from studies on sexualities where the researchers have taken an expansive reading of ethical protocols, keeping in mind the best way of producing knowledge while meaning no harm to the participants and place ecologies involved. An expansive reading provides for situation specific ethical practice. Such sensitivity and care, and the ethic of beneficence should guide research on contexts that demand pushing of boundaries of ethical practice, especially contexts that rarely fit in neatly with normative application of protocols.

\section{REFERENCES}

[1] Adler, S., \& Brenner, J. (1992). Gender and space: lesbians and gay men in the city. International journal of urban and regional research, 16(1), 24-34.

[2] Bech, H. (1997). When men meet: Homosexuality and modernity. University of Chicago Press.

[3] Bhairannavar, K. (2010, March 3-5). Internet and sexuality: exploring online homosexual space in Delhi [paper Presentation]. International Seminar: Contextualising Geographical Approaches to Studying Gender in Asia, New Delhi, India.

[4] Bhairannavar, K. (2016). More-than-closet' geographies: Exploring queered spaces through the sexual lives of men in Delhi [PhD thesis]. National University of Singapore https://scholarbank.nus.edu.sg/handle/10635/135541

[5] Brown, G. (2008). Ceramics, clothing and other bodies: affective geographies of homoerotic cruising encounters. Social \& Cultural Geography, 9(8), 915-932.

[6] Brown, M. P. (2000). Closet space: Geographies of metaphor from the body to the globe (Vol. 12). Psychology Press.

[7] Campbell, J. E. (2014). Getting it on online: Cyberspace, gay male sexuality, and embodied identity. Routledge.

[8] Carrier, J. (1995). De los otros: Intimacy and homosexuality among Mexican men. New York: Columbia University Press

[9] Chauncey, G. (2008). Gay New York: Gender, urban culture, and the making of the gay male world, 1890-1940. Hachette UK.

[10] Crang, P. (1994). It's showtime: on the workplace geographies of display in a restaurant in southeast England. Environment and Planning D: Society and Space, 12(6), 675-704.

[11] Dowling, R. (2009). Ethical issues in research. In International encyclopedia of human geography (pp. 595600). Elsevier.

[12] England, K. V. (1994). Getting personal: Reflexivity, positionality, and feminist research. The professional geographer, 46(1), 80-89.

[13] Humphreys, L. (1970). Tearoom Trade: Impersonal Sex in Public Places. Chicago: Aldine Publishing Company.

[14] Lenza, M. (2004). Controversies surrounding Laud Humphreys' tearoom trade: An unsettling example of 
politics and power in methodological critiques. International Journal of Sociology and Social Policy.

[15] McLelland, M. J. (2002). Virtual ethnography: Using the Internet to study gay culture in Japan. Sexualities, 5(4), $387-$ 406.

[16] Neuman, W. L. (1997). Social Research Methods: Qualitative and Quantitative Approaches. Boston: Allyn and Bacon.

[17] Shahani, P. (2008). Gay Bombay: Globalization, love and (be) longing in contemporary India. SAGE Publications India.

[18] James, T., \& Platzer, H. (1999). Ethical considerations in qualitative research with vulnerable groups: Exploring lesbians' and gay men's experiences of health care-A personal perspective. Nursing ethics, 6(1), 73-81.

[19] Valentine, G., Butler, R., \& Skelton, T. (2001). The ethical and methodological complexities of doing research with 'vulnerable' young people. Ethics, Place \& Environment, 4(2), 119-125. 